\title{
PROSTHETIC COMPLICATIONS AND MAINTENANCE OF IMPLANT RETAINED MAXILLARY AND MANDIBULAR OVERDENTURES CONSTRUCTED WITH FULLY BALANCED AND LINGUALIZED OCCLUSAL SCHEMES : RANDOMIZED CONTROL CLINICAL STUDY
}

\author{
Sahar A. Kortam* and Reem M. Abdeen**
}

\begin{abstract}
Aim: The purpose of this study was to evaluate the prosthetic complications and maintenance of implant retained maxillary and mandibular overdentures constructed with fully balanced and lingualized balanced occlusal schemes.

Materials and methods: Eight participants with edentulous maxillary and mandibular ridges received 4 implant fixtures in the lateral incisor and first premolar areas of maxilla and 2 implant fixtures in the cuspid areas of the mandible using the submerged surgical protocol. Maxillary and mandibular overdentures were constructed with either fully balanced occlusal scheme (group I) or lingualized balanced occlusal scheme (group II) and connected to the implants with Locator attachments after 6 months of implant insertion. Evaluation of prosthetic maintenance and complications for both maxillary and mandibular dentures in both groups were made after one year of denture insertion.
\end{abstract}

Results: For maxillary and mandibular overdentures, group I had significant higher incidence of screw loosening, insert wear and insert replacement than Group II. While Group II had higher incidence of teeth wear than Group I. No significant difference in denture reline and insert distortion between both groups was noted. For mandibular overdentures, group I was associated with significant higher mucositis, soreness, ulcer decubitus than Group II. For maxillary overdentures, no significant difference in mucositis, soreness, hyperplasia or flabby ridges between groups was noted.

Conclusion: Within the limitations of this study, Lingualized balanced occlusal concept is recommended for maxillary and mandibular implant overdentures as it was associated with significant lower prosthetic and soft tissue complications than fully balanced occlusal concept. However, it had significant higher tooth wear and may need teeth replacement.

* Lecturer of Removable Prosthodontics, Faculty of Dentistry, Beni-Seuf University.

** Lecturer of Removable Prosthodontics, Faculty of Dentistry, Misr International University. 


\section{INTRODUCTION}

For the majority of patients, an overdenture on two implants is the first choice of treatment when complaining about the lack and stability of their mandibular denture ${ }^{1,2}$. Such restoration are substantially cost effective to fabricate, easier to clean, can overcome appearance and speech problems and give increased satisfaction of the patients ${ }^{3,4}$ Edentulous patients with maxillary complete denture and mandibular implant supported overdentures often subjected to degeneration changes in the maxillary edentulous arch similar to that observed with the traditional combination syndrome due to increased biting forces on maxillary anterior regions ${ }^{5}$. Prevention of anterior occlusal pressure, and support and stabilization of the maxillary dentures with implants are mandatory in elimination of these atrophic changes $^{6}$. Additionally, implant retained maxillary overdentures could be effective treatment options for patients complaining from insufficient retention and stability of conventional maxillary dentures ${ }^{7}$, such overdentures provide proper phonetics, adequate restoration of alveolar bone loss and lip support, good aesthetics and hygiene access that is not possible with a fixed maxillary prosthesis ${ }^{8}$. Compared with the mandible, implant-retained maxillary overdentures had several complications, such as low bone density and volume, non-axial implants, and position of teeth away from the implant axis, which increase stress transmission to the implants ${ }^{9}{ }^{10}$. Thus, more implants are needed for maxilla than that of the mandible ${ }^{11}$, so a minimum of 4 implants a consensus in the reviewed literature. ${ }^{8,12-14}$

Several attachments can be used to retain overdentures to the implants such as splinted (bar/ clip) or non-splinted (ball, stud and magnetic) attachments. Bar attachments distribute load between the implants, can be used with divergent implants ${ }^{15}$, had reduced rate of prosthetic complications ${ }^{16}$ and provide horizontal stability when the ridge is resorbed ${ }^{17}$. However, unsplinted anchorage systems require less inter-arch distance especially within implant retained over-denture prosthesis involving both maxilla and mandible, are easier to clean and more economical, as well as less technique sensitive when managing splinted designs ${ }^{18}$. The locator attachments are solitary, widely used to retain overdentures, as they are self-seated, resilient, have effective retentive forces ${ }^{19,20}$. Locator attachments also are available in different heights, durable; and can be used with increased implant angulation ${ }^{21-24}$. Moreover, repair and renewal are quick and straightforward ${ }^{19,25}$. Locator attachments showed favorable clinical and radiographic outcomes ${ }^{26}$, masticatory function ${ }^{27}$, and patient satisfaction ${ }^{28}$ compared to other attachment systems.

It has been reported that the biomechanically controlled occlusion is profound for clinical success and longevity of implants. So sound biomechanical principles have to be followed during establishment of occlusion for any implant supported or retained prosthesis, so as to direct occlusal forces mainly along the long axis of implant and minimize the offcentered forces ${ }^{29}$.

So enhancing preservation of osseointegration can be accomplished by decreasing lateral stresses that result when vertical force is applied on inclined occlusal surface ${ }^{29}$. For implant overdentures, the commonly used occlusal schemes are fully balanced occlusion and lingualized balanced occlusion. Lang and Razzoog ${ }^{30}$ recommended lingualized occlusion for implant overdentures. Despite the fact that fully balanced occlusion is recommended by several authors to improve stability of implant overdentures, there are a lot of studies that compared it with the lingualized occlusion regarding their effect on loss of marginal bone surrounding the implants and the prognosis of osseointegration, where the results of both occlusal schemes has been proved to be satisfied $^{31}$. 
However, reviewing the literature, the evaluation of opposing occlusal schemes on the prosthetic complication and maintenance of implant supported overdentures are relatively scarce ${ }^{11,32}$ especially in those cases of maxillary implant supported overdenture opposed by mandibular implant supported overdenture. Therefore, the aim of this study was to evaluate prosthetic complications and maintenance of implant retained maxillary and mandibular overdentures constructed with fully balanced and lingualized balanced occlusal schemes. The null hypothesis was that there will be no significant difference in prosthetic complications and maintenance between both occlusal schemes.

\section{MATERIALS AND METHODS}

\section{Patients enrollment}

Eight patients (4 males and 4 females) with average age 50-65 years were recruited from the patients attended at the clinic of the Removable Prosthodontic Department, faculty of dentistry, Beni-Seuf University to receive implant retained overdentures. The inclusion criteria include the following:

1. Completely edentulous maxillary and mandibular ridges with healthy mucosa and absence of remaining roots.

2. All patients suffering from insufficient retention and stability of their maxillary and mandibular conventional dentures due to ridge resorption.

3. All patients had adequate bone quantity (width and height) in the anterior maxillary and mandibular ridges ${ }^{33}$ and adequate bone quality ${ }^{34}$ (as verified by preoperative cone beam CT).

4. Absence of smoking habits.

5. Adequate interarch space to accommodate maxillary and mandibular over-dentures

Patients who had bone metabolic disorders, and diseases that may complicate surgical procedure as liver, heart, auto-immune diseases, radiation to head and neck and diabetes mellitus were excluded. The study protocol and objectives were described to the subjects, and they all signed consents. The study followed the guidelines of committee of ethics of the Faculty of Dentistry, Beni-Seuf University. Patients were classified into 2 groups using balanced random selection with equal gender distribution in each group: Group I (GI); included 4 patients who received 4 implant-retained maxillary overdentures and 2-implant retained mandibular overdentures constructed using fully balanced occlusal scheme, and group II (GII); included 4 patients who received 4 implant-retained maxillary overdentures and 2-implant retained mandibular overdentures constructed using lingualized balanced occlusal scheme.

\section{Surgical and prosthetic procedures}

Maxillary and mandibular old dentures were revised for perfect adaptation and occlusion to be used as a radiographic template where Gutta purcha were fixed to polished surfaces the dentures at variable heights from occlusal plane ${ }^{35}$. The location and angulation of the fixtures and the correct implant length were assessed using a radiographic stent that was scanned twice using Cone Beam Computed Tomography (CBCT, i- CAT Vision ${ }^{\circledR}$, Imaging Sciences International, Hatfield, PA, USA), as the patient wore the upper and lower radiographic template to be firstly imaged while he was biting guided by putty occlusal index , and then upper and lower templates occluding together were secondly scanned outside the patient mouth in the same position guided by occlusal index. The two images were fused together using 3D image-based software (OnDemand 3D App Software; CyberMed Inc) to construct a tissue supported surgical guide by prototyping technology.

Four implants were planned in lateral incisor and $1^{\text {st }}$ premolar areas between the maxillary sinuses. Two implants were planned in the canine areas of the mandible. A surgical kit including sleeves and 
standardized drills (supplied by the radiologist) was used for osteotomy preparation.

All surgeries were carried out with infiltration anesthesia (lidocaine with epinephrine). The osteotomy sites were prepared following the drilling sequence provided by the manufacturer's surgical universal kit. A crestal incision was made in the maxillary and mandibular arches with minimal flap reflection. The maxillary template was fixed using anchor pins. Four implants (Dentium Co., Seoul, Korea), were inserted after osteotomy preparation. Cover screws were connected to the implants. The flap was covered by interrupted sutures and the old maxillary dentures were relieved and relined with resilient liners after refining the occlusion. Postoperative medications include;
Antibiotics (amoxicillin $625 \mathrm{mg}+$ clavulanic acid $125 \mathrm{mg}$, Augmentin $\left.{ }^{\circledR} 1 \mathrm{gm}\right)$, Corticosteroids (Dexamethasone ${ }^{\circledR}$ ) injection immediately after surgery to reduce postoperative edema and inflammation. Anti-inflammatory medication (ibuprofen ${ }^{\circledR}, 600 \mathrm{mg}$ ) was administered for 5 days postoperatively. The procedure was repeated for mandibular implants after one month to allow healing of maxillary soft tissue (fig 1).

Post-operative panoramic radiograph was made (fig 2).

For both groups, six months after implant insertion, the maxillary and two weeks later, primary alginate impression was made and poured to get primary models on which custom trays

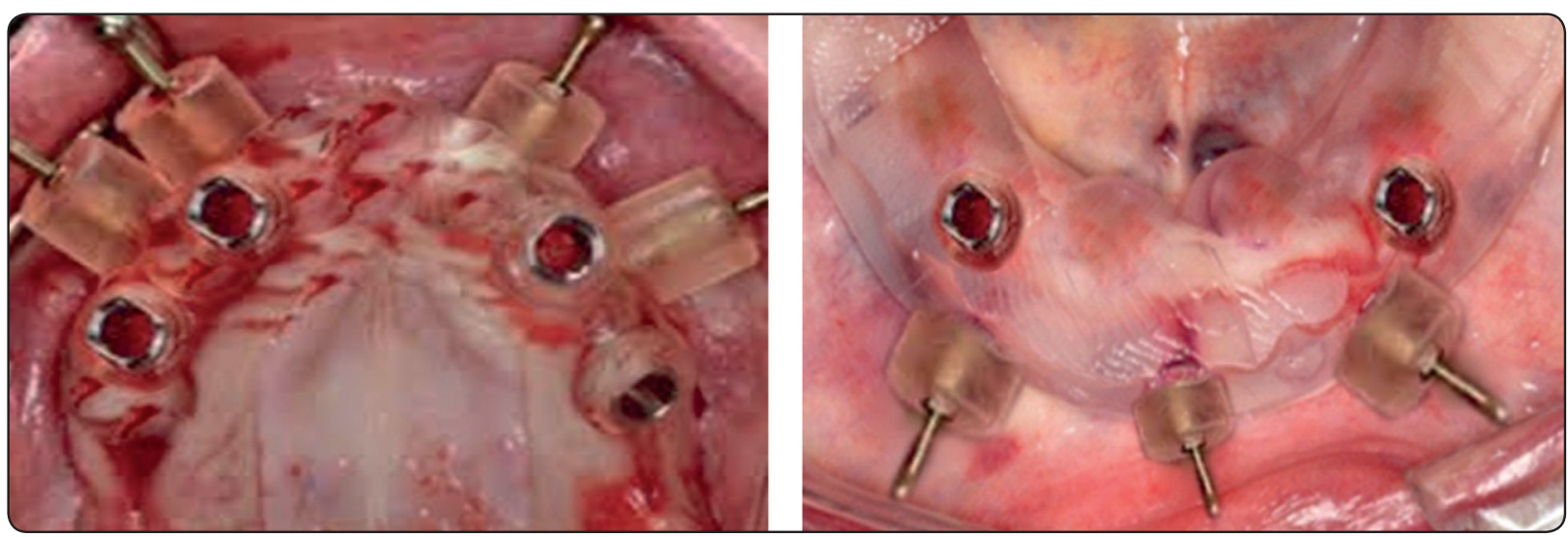

Fig. (1): CAD- CAM Surgical Guides Used for Flapless surgical placement of: maxillary and mandibular implants.

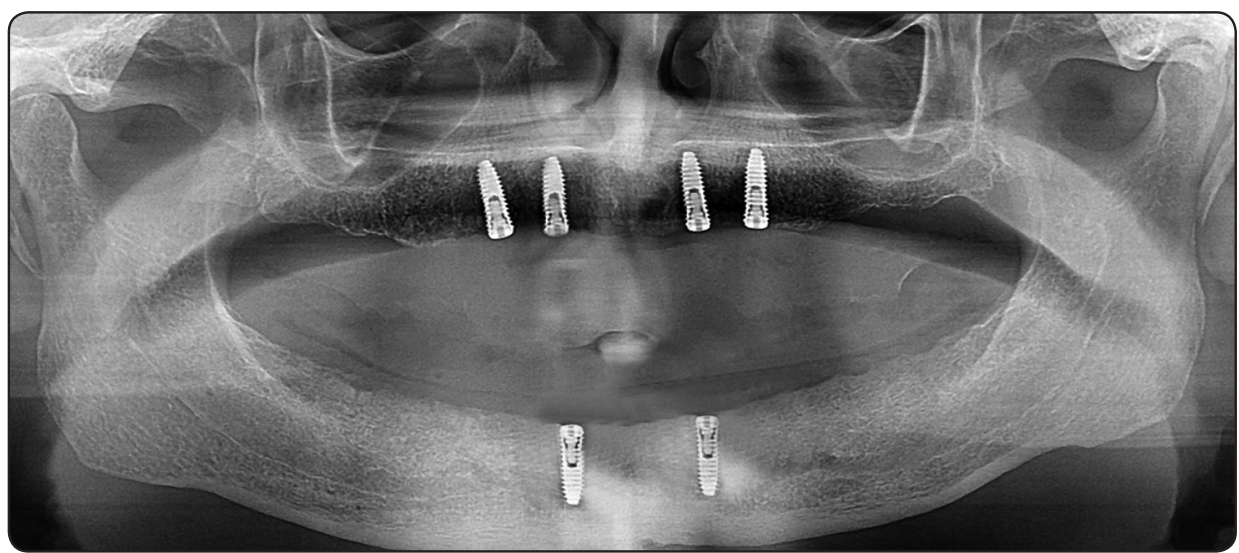

Fig. (2): Post-operative panoramic radiograph 
were made. After border molding of the trays, openings opposite to the implants were made. Long impression copings were connected to the implants and open tray maxillary and mandibular impressions were made, analogues were attached to the copings and impressions were poured to obtain master casts. Occlusion blocks were constructed to be ready for recording the jaw relation. The occlusal plane was adjusted and the maxillary cast was mounted on a semi-adjustable articulator (Bio-art semi-adjustable articulator. A7 Plus. Brazil) using maxillary face transfer (Bio-art face bow, Brazil), while the lower cast was mounted using centric relation record following check bite technique. Protrusive record was done following the wax-wafer technique to modify the horizontal guidance of the articulator. The Lateral guidance was modified using the equation $\mathrm{L}=\mathrm{H} / 8+12$ (Hanau formula). For group I, setting up of anatomic $33^{\circ}$ cusp angle crosslinked acrylic teeth (Acrostone) was carried out according to fully balanced occlusion concept. So that the anterior teeth were arranged with sufficient vertical overlap as allowed by adequate aesthetics and phonetics, then acceptable horizontal overjet was established to avoid anterior interference in lateral and protrusive mandibular movements. In eccentric movement, the posterior teeth were set to provide bilateral occlusal balance for a range of 2-3 $\mathrm{mm}$ around centric relation, hence the lower buccal cusp ridges were adjusted to contact the upper buccal cusp ridges, and the lower lingual cusp ridges contact the upper lingual cusp ridges on the working side. While on the balancing side, the lower buccal cusps contact with the lingual cusps (fig 3a). For group II, Posterior anatomic teeth (cusp angle $33^{\circ}$ ) were used for maxillary denture and preferred to be with prominent lingual cusps, while semianatomic teeth with $20^{\circ}$ cusp angle were selected for mandibular denture posterior teeth were set according to the lingualized occlusion concept, so mandibular buccal cusps were reduced by selective grinding to be out of occlusal contact in both centric and eccentric positions, and only maxillary lingual cusps make occlusal contact with the mandibular teeth in all jaw positions (fig 3b). After try in of trail denture bases, Locator abutments (Dentium Co., Seoul, Korea) were threaded to the analogues on the models and white processing inserts were snapped on the locator abutments before packing of acrylic resin.

The dentures were processed in usual manner, finished and polished, and the occlusion in both groups was refined by laboratory remounting. Locator abutments were screwed in patient mouth (fig 4). Processing inserts were replaced by blue nylon insert (extra light retention) was used (fig 5). Then occlusion was checked and equilibrated to achieve stable occlusal contact in centric and

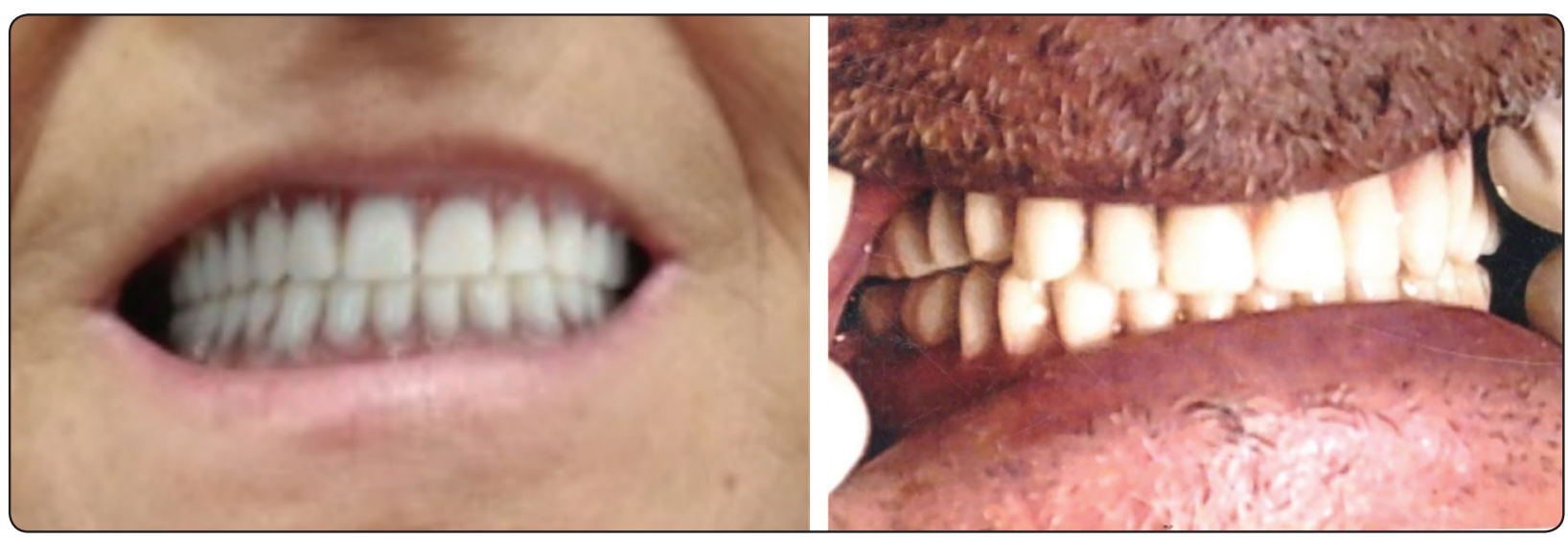

Fig. (3) a: Fully balanced occlusal scheme, b: Lingualized balanced occlusal scheme 


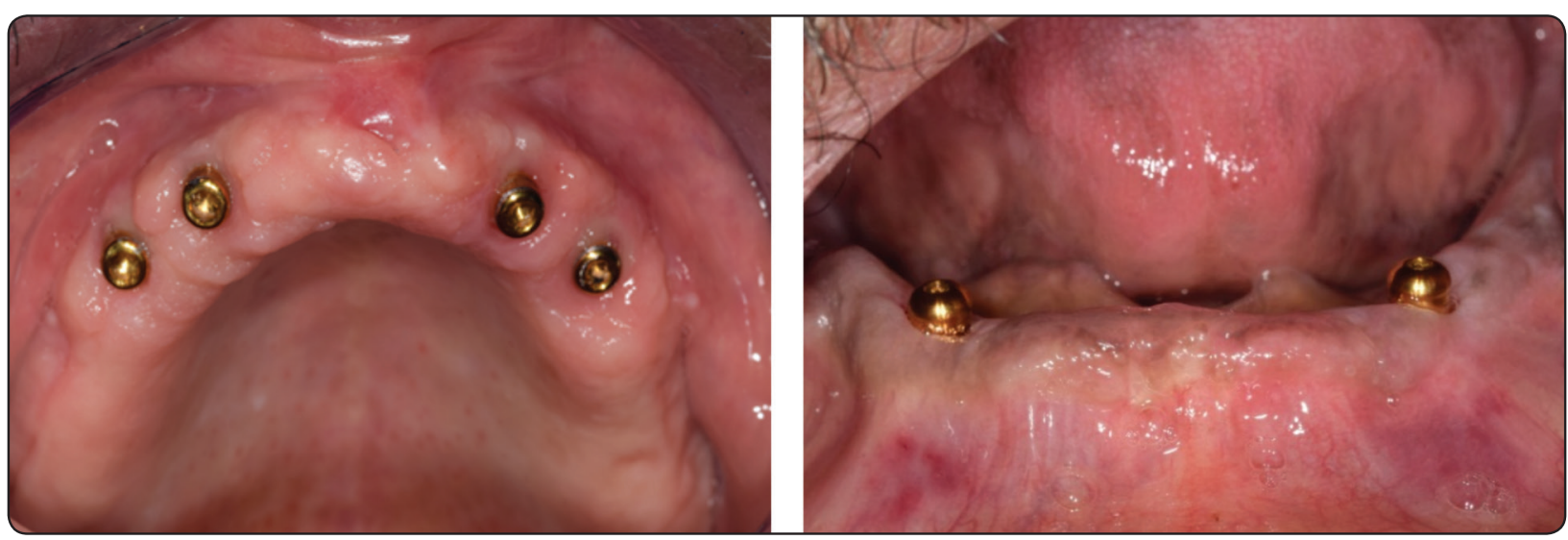

Fig. (4): Locator abutments screwed in patient mouth for maxillary and mandibular overdentures

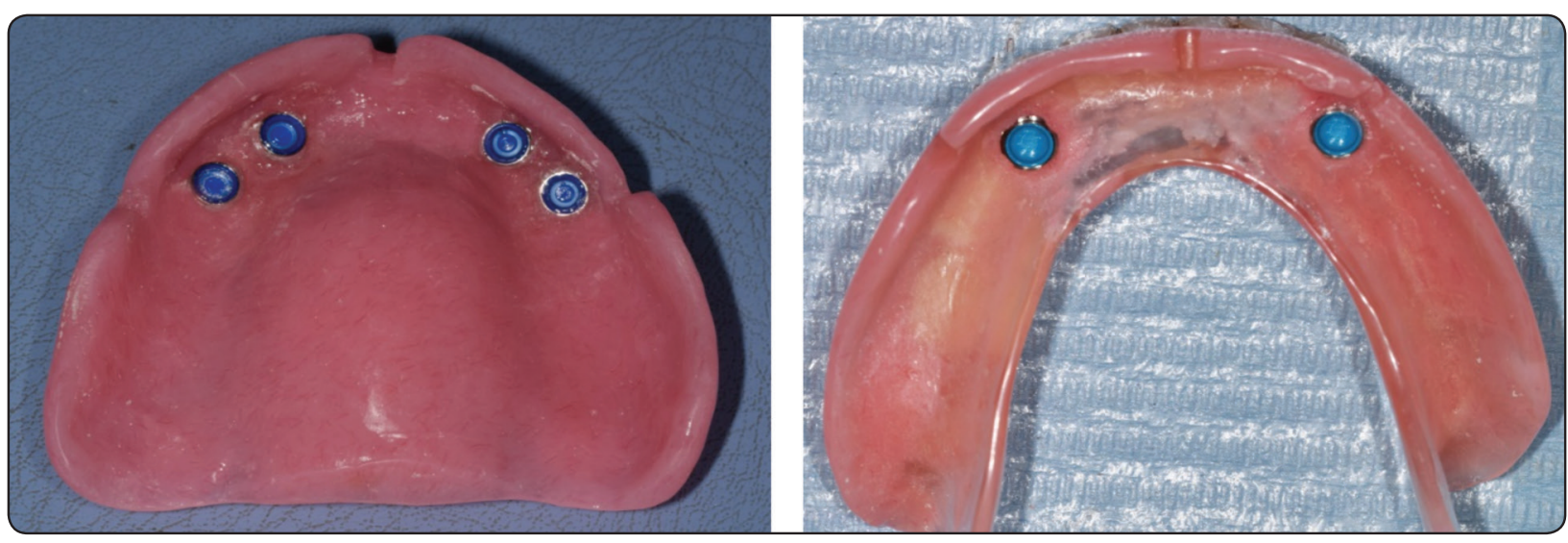

Fig. (5): Nylon inserts in the fitting surface of maxillary and mandibular overdentures

eccentric relations using clinical remounting on the articulator using new jaw relations records, then the occlusion was rechecked again in the patient mouth using articulating paper. The upper and lower overdentures were delivered to the participants of both groups, and the oral hygiene instructions were given to all patients.

\section{Evaluation of prosthetic maintenance and com- plications}

Evaluation of prosthetic maintenance and complications for both maxillary and mandibular dentures in both groups were made after one year of denture insertion, as certain schedule ${ }^{36,37}$ was followed:
1. Prosthetic complications of the implants (implant fracture, screw loosening, screw fracture) attachments (wear, distortion, fracture, replacement), overdentures (reline, remake, fracture, teeth wear, teeth separation or fracture).

2. Soft tissue complications (mucositis, soreness, ulcer decubitus, hyperplasia and flabby ridge) under the dentures.

\section{Statistical analysis}

SPSS ${ }^{\circledR}$ software version 25 (SPSS Inc., Chicago, IL, USA) was used for data analysis. The implant and attachment complications were calculated on implant level. Other prosthetic and soft tissue complications were calculated on patient 
level. The descriptive statistics of both prosthetic and soft tissue complications for both groups were calculated in terms of frequency and percentages using frequency distribution (contingency) tables. To test the difference in proportions of prosthetic and soft tissue complications between groups, Chi square test was used. P-values $<0.05$ were considered to be significant.

\section{RESULTS}

The frequency distribution of the incidence of prosthetic events of maxillary and mandibular dentures in both groups is presented in table 1. For mandibular overdentures, no abutment fracture, screw fracture, insert fracture, denture remakes, denture fractures, teeth separation and teeth fractures occurred in both groups. Fully balanced occlusal concept was associated with significant higher incidence of screw loosening, insert wear, insert replacement than lingualized balanced occlusal concept. While lingualized balanced occlusal concept was associated with significant higher incidence of teeth wear than fully balanced occlusal concept. No significant difference in denture reline and insert distortion between both occlusal concepts was noted. For maxillary overdentures, no abutment fracture, screw fracture, insert fracture, denture remakes, denture fractures, teeth separation and teeth fractures occurred in both groups. Fully balanced occlusal concept was associated with significant higher incidence of screw loosening, insert wear, insert replacement than lingualized balanced occlusal concept. While lingualized balanced occlusal concept was associated with significant higher incidence of teeth wear than fully balanced occlusal concept. No significant difference in denture reline and insert distortion between both occlusal concepts was noted.

The frequency distribution of the incidence of soft tissue complications of maxillary and mandibular dentures in both groups is presented in table 2. For mandibular overdentures, fully balanced occlusal concept was associated with significant higher mucositis, soreness, ulcer decubitus than lingualized occlusal concept. No mucosal hyperplasia or flabby ridges occurred in the mandibular arch in both groups. For maxillary overdentures, no significant difference in mucositis, soreness, hyperplasia or flabby ridges between groups was noted. No ulcer decubitus occurred in the maxillary ridge in both groups.

TABLE (1) Frequency distribution of incidence of prosthetic complications

\begin{tabular}{|c|c|c|c|}
\hline & $\begin{array}{l}\text { Bilateral } \\
\text { balanced }\end{array}$ & Lingualized & $\begin{array}{c}\text { Chi square } \\
\text { (p value) }\end{array}$ \\
\hline \multicolumn{4}{|c|}{ Mandibular denture } \\
\hline \multicolumn{4}{|c|}{ Locator abutments (implant level) } \\
\hline abutment fracture & 0 & 0 & 1.00 \\
\hline screw loosening & 4 & 0 & $.021 *$ \\
\hline screw fracture & 0 & 0 & 1.00 \\
\hline \multicolumn{4}{|c|}{ Locator housing and inserts (implant level) } \\
\hline Insert wear & 5 & 1 & $.039 *$ \\
\hline Insert distortion & 3 & 1 & .24 \\
\hline Insert fracture & 0 & 0 & 1.00 \\
\hline Insert replacement & 8 & 2 & $.012 *$ \\
\hline \multicolumn{4}{|c|}{ Overdentures (patient level) } \\
\hline Denture reline & 2 & 1 & .52 \\
\hline Denture remake & 0 & 0 & 1.00 \\
\hline Denture fracture & 0 & 0 & 1.00 \\
\hline Teeth wear & 1 & 4 & $.021 *$ \\
\hline Teeth separation & 0 & 0 & 1.00 \\
\hline Teeth fracture & 0 & 0 & 1.00 \\
\hline \multicolumn{4}{|c|}{ Maxillary denture } \\
\hline \multicolumn{4}{|c|}{ Locator abutments } \\
\hline abutment fracture & 0 & 0 & 1.00 \\
\hline screw loosening & 9 & 3 & $.028 *$ \\
\hline screw fracture & 0 & 0 & 1.00 \\
\hline \multicolumn{4}{|c|}{ Locator housing and inserts } \\
\hline Insert wear & 7 & 2 & $.049 *$ \\
\hline Insert distortion & 4 & 1 & .14 \\
\hline Insert fracture & 0 & 0 & 1.00 \\
\hline Insert replacement & 11 & 3 & $.004 *$ \\
\hline \multicolumn{4}{|l|}{ Overdentures } \\
\hline Denture reline & 1 & 0 & .31 \\
\hline Denture remake & 0 & 0 & 1.00 \\
\hline Denture fracture & 0 & 0 & 1.00 \\
\hline Teeth wear & 1 & 4 & $.021 *$ \\
\hline Teeth separation & 0 & 0 & 1.00 \\
\hline Teeth fracture & 0 & 0 & 1.00 \\
\hline
\end{tabular}


TABLE (2): Frequency distribution of incidence and percentage of soft tissue complications

\begin{tabular}{|c|c|c|c|}
\hline & $\begin{array}{l}\text { Bilateral } \\
\text { balanced }\end{array}$ & Lingualized & $\begin{array}{c}\text { Chi square } \\
\text { (p value) }\end{array}$ \\
\hline \multicolumn{4}{|c|}{ Mandibular denture (patient level) } \\
\hline Mucositis & 3 & 1 & $.028 *$ \\
\hline Soreness & 3 & 1 & $.028 *$ \\
\hline Decubiti's ulcer & 2 & 0 & $.049 *$ \\
\hline Hyperplasia & 0 & 0 & 1.00 \\
\hline Flabby ridge & 0 & 0 & 1.00 \\
\hline \multicolumn{4}{|c|}{ Maxillary denture (patient level) } \\
\hline Mucositis & 2 & 2 & 1.00 \\
\hline Soreness & 1 & 0 & .28 \\
\hline Decubiti's ulcer & 0 & 0 & 1.00 \\
\hline Hyperplasia & 2 & 1 & .46 \\
\hline Flabby ridge & 2 & 1 & .46 \\
\hline
\end{tabular}

\section{DISCUSSION}

It has been emphasized the role of occlusion as a key factor in not only implant success prosthesis but its longevity, as it has been mentioned that most of the problems of the implants showed between the first and sixth week post-insertion are directly related to the occlusion ${ }^{38}$. Accordingly, in our study along one-year follow-up period, all complications of implant retained maxillary overdenture opposing mandibular implant retained overdenture constructed with two different occlusal schemes, it could be said that forces exerted by both occlusal schemes were within the physiological limits of the bone supporting the implants. Hence no massive failures could be seen like implant loosening and fracture of either abutments or screws. Also there may be other factors that modulate the occlusal pressure transmitted to the implants. Accurate placement of implants using stereolithographic CAD-CAM surgical guide that enabled accurate actual placement of implants concomitant with virtual planning that ensured occlusal forces parallel with long axis of implant. Additionally, for mandibular and maxillary overdentures, no abutment fracture, or screw fracture occurred. This might be due to the acrylic artificial teeth having high shock absorbability and dampening effect which reduce occlusal force transmission to the implants $^{39}$ and could be responsible for reduced abutment and screw fracture. Moreover, selection of locator attachment system might have a role in reducing occlusal stresses, as the vertical resiliency of the nylon inserts ${ }^{40}$ provided for stress relief and hence reduce stresses on the implants with subsequent decreasing of abutment and screw fracture. Also, the vertical and hinge resiliency of the nylon inserts could be responsible for absence of insert fracture. Therefore, inserts are more prone to wear or distortion by increased occlusal load rather than fracture.

Moreover, the reduced height and buccolingual dimension of the locator attachments could be accounted for absence of denture remakes, denture fractures, teeth separation and teeth fractures in both groups. As, Locator attachments occupy less prosthetic space within the denture base. Consequently, it reduces denture base deformation and fracture ${ }^{40,41}$. The total height of locator attachments is approximately $2.5 \mathrm{~mm}$. This allowed an increase in the overlaying acrylic resin ${ }^{42}$ and decreased denture base deformation, decrease teeth separation and fracture in both groups. Furthermore, the use of full palatal coverage in the maxillary overdenture strengthen the denture base and reduce denture fractures.

However, fully balanced occlusal concept was associated with significant higher incidence of screw loosening, insert wear, insert replacement than lingualized balanced occlusal concept. This may reflect the increased occlusal pressure and load transmission to the locator attachments when fully balanced occlusion was used compared to lingualized occlusion. This could be attributed to the architecture of fully balanced occlusion that has more occlusal contact points on functional and 
non-functional cusps on the loading (chewing) side during lateral mandibular excursions as well as during protrusive movements of mastication ${ }^{43}$. Moreover, fully occlusal concept using anatomic teeth, so occlusal disharmonies (locking of occlusion) may occur by settling of denture base (as a result of mucosal resiliency and vertical resiliency of the nylon inserts) which is difficult to be corrected ${ }^{43}$. This may increase horizontal stresses and lateral forces applied to the implants due to cusp contact on the inclined planes of artificial teeth. This caused occlusal pressure that could be responsible for increased screw loosening, insert wear, and insert replacement.

In contrast, in lingualized occlusion, the only functional palatal cusps contact during centric and eccentric excursions with mortar and pestle style that transmit load to a point only (central fossa) with subsequent less lateral forces transmitted to the denture and the underlying implant system ${ }^{44}$,so the lingualized occlusion provide freedom in lateral movement as well as reduced occlusal multiplicity of contact without locking interference when denture settling occurs, additionally the reduced lateral forces are due to fewer number of cusp contact on the inclined planes during lateral and protrusive movements with increased denture stability, hence less denture movement and less occlusal pressure transmitted to the supporting implants and the retaining attachments ${ }^{44}$.

The increased prosthetic complications (increased screw loosening, insert wear, and insert replacement) that was seen in both groups could also be attributed to locator attachment demerits that were reported in other studies in which the patients wear either mandibular overdenture opposing complete denture ${ }^{45}$ or maxillary and mandibular overdentures with locator attachments ${ }^{46,47}$. These complications may be due to absence of retention in the Locator attachment due to wear and distortion of the nylon inserts which need replacement of the nylon male component. This concur with Kleis et $\mathrm{al}^{25}$ who concluded that follow-up for patients with locator attachment is needed to manage deformation and damage of nylon inserts. Furthermore, it has been recently mentioned ${ }^{48}$ that the use of more implants reduce the number of prosthetic complications, and damage of the nylon inserts of the Locator attachment. However, the increased number of implants for maxillary overdentures in this study did not reduce the incidence of prosthetic complications. This could be attributed to the increased labial inclination of the implants in the premaxillary region due to the anatomy of the bone. This creates angulation between anterior and posterior locator attachments. This angulation was reported to increase the wear and damage of the locator nylon inserts..$^{24,49-51}$

The lingualized balanced occlusal concept was associated with significant higher incidence of teeth wear than fully balanced occlusal concept. This may be attributed to the point of contact of the functional palatal cusps to the opposing fossa as stated previously which increase occlusal forces on this point and accelerate wear of the contacting cusps. This may cause possible reduction of masticatory efficiency of tooth, and loss vertical dimension of occlusion over time. Therefore, it is recommended for patients to perform regular recalls to evaluate occlusal contact and replace the worn teeth if needed.

For mandibular overdentures, fully balanced occlusal concept was associated with significant higher mucositis, soreness, ulcer decubitus than lingualized occlusal concept. This could be due to higher incidence of occlusal contacts leading to increased occlusal forces on the supporting bone and the overlying delicate mucosa of the mandibular ridge, as the overdenture hinges around an imaginary line connecting the canine implants in the mandible causing free overdenture rotation during function which may result in enhanced posterior loading as noted by Naert, et al..$^{52}$ No mucosal hyperplasia or flabby ridges occurred in the mandibular arch in both groups thanks to the effective implant support in the anterior areas. Also, the smooth surface of locator attachments 
provides easier oral hygiene and cleaning without causing peri-implant mucosal inflammation or gingival hyperplasia ${ }^{24}$. For maxillary overdentures, no ulcer decubitus occurred in the maxillary ridge in both groups. This may be due to the increased implant support provided by the 4 implants which decrease overdenture rotation during function, also the excessive area of maxillary keratinized mucosa provides more tissue support with little or no mucosal irritation. On contrary, mandibular nonkeratinized mucosa having diminished supportive area.

\section{CONCLUSION}

Within the limitations of this study, Lingualized balanced occlusal concept is recommended for opposing maxillary and mandibular implant overdentures as it was associated with significant lower prosthetic and soft tissue complications than fully balanced occlusal concept. However, it had significant higher tooth wear and may need teeth replacement.

\section{REFERENCES}

1. Feine JS, Carlsson GE, Awad MA, Chehade A, Duncan WJ, Gizani S et al. The McGill consensus statement on overdentures. Mndibular two-implant overdentures as first choice standard of care for edentulous patients. Gerodont. 2002; 19:3-4.

2. Naert I, Alsaadi G, Quirynen M. Prosthetic aspects and patient satisfaction with two-implant-retained mandibular overdentures: a 10-year randomized clinical study. Int J Prosthodont. 2004; 17:401-10.

3. MacEntee MI, Walton JN, Glick N. A clinical trial of patient satisfaction and prosthodontic needs with ball and bar attachments for implant-retained complete overdentures: three-year results. J Prosthet Dent. 2005; 93:28-37

4. Kronstrom M, Carlsson GE. An international survey among prosthodontists of the use of mandibular implant-supported dental prosthesis. J Prosthodont. 2019; 28:622-6.

5. Cabianca M. Combination syndrome: treatment with dental implants. Implant Dent. 2003; 12:300-5.
6. Tolstunov L. Combination syndrome: classification and case report. J Oral Implantol. 2007; 33:139-51.

7. Emami E, De Souza R, Kabawat M, Feine J . The impact of edentulism on oral and general health. Inter $\mathrm{J}$ of Dent. 2013; 2013: 7 .

8. Al-Zubeidi M, Alsabeeha N, Thomson W, Payne A. Patient satisfaction with maxillary 3-implant overdentures using different attachment systems opposing mandibular 2-implant overdentures. Clin Impl Dent and Related Res. 2012; 14:11-9.

9. Kronstrom M, Widbom C, Soderfeldt B. Patient evaluation after treatment with maxillary implant-supported overdentures. Clin Implant Dent Relat Res. 2006; 8:39-43.

10. Akca K, Akkocaoglu M, Comert A, Tekdemir I, Cehreli MC. Human ex vivo bone tissue strains around immediately loaded implants supporting maxillary overdentures. Clin Oral Implants Res. 2005; 16:715-22.

11. Zou D, Wu Y, Huang W, Wang F, Wang S, Zhang Z et al. A 3-year prospective clinical study of telescopic crown, bar, and locator attachments for removable four implant-supported maxillary overdentures. Int J Prosthodont. 2013; 26:566-73.

12. Kiener P, Oetterli M, Mericske E, Mericske-Stern R. Effectiveness of maxillary overdentures supported by implants: maintenance and prosthetic complications. Int $\mathrm{J}$ Prosthodont. 2001; 14:133-40.

13. Slot W, Raghoebar GM, Vissink A, Huddleston Slater JJ, Meijer HJA. A systematic review of implant-supported maxillary overdentures after a mean observation period of at least 1 year. J Clin Periodontol 2010; 37: 98- 110.

14. Andreiotelli M, Strub J-R. Prosthodontic complications with implant overdentures: a systematic literature review. Int J Prosthodont 2010; 23: 195- 203.

15. Carpentieri JR. Clinical protocol for an overdenture bar prosthesis fabricated with CAD/CAM technology. Pract Proced Aesthet Dent. 2004; 16:755-7.

16. Van Kampen F, Cune M, van der Bilt A, Bosman F. Retention and post insertion maintenance of bar-clip, ball and magnet attachments in mandibular implant overdenture treatment: an in vivo comparison after 3 months of function. Clin Oral Implants Res 2003; 14: 720- 26.

17. van der Bilt A, van Kampen FM, Cune MS. Masticatory function with mandibular implant-supported overdentures fitted with different attachment types. Eur J Oral Sci. 2006; 114:191-6. 
18. Chandan K, Agrawat P, Mistry G, Singh R. Implant Supported Overdenture Attachments- A Review. JDMS. 2017; 16: $87-91$

19. Chung KH, Chung CY, Cagna DR, Cronin RJ, Jr. Retention characteristics of attachment systems for implant overdentures. J Prosthodont. 2004; 13:221-6.

20. Evtimovska E, Masri R, Driscoll CF, Romberg E. The change in retentive values of locator attachments and hader clips over time. J Prosthodont. 2009; 18:479-8.

21. Ahuja S, Cagna DR. Classification and management of restorative space in edentulous implant overdenture patients. J Prosthet Dent. 2011; 105:332-37.

22. Mackie A, Lyons K, Thomson WM. Mandibular two-implant overdentures: three-year prosthodontic maintenance using the locator attachment system. Int J Prosthodont. 2011; 24:328-31.

23. Uludag B, Polat S, Sahin V. Effects of implant angulations and attachment configurations on the retentive forces of locator attachment-retained overdentures. Int J Oral Maxillofac Implants. 2014; 29:153-57.

24. Srinivasan M, Kalberer N, Maniewicz S. Implant overdentures retained by self-aligning stud-type attachments: a clinical report. J Prosthet Dent. 2020; 123:6-14.

25. Kleis WK, Kammerer PW, Hartmann S, Al-Nawas B, Wagner W. A comparison of three different attachment systems for mandibular two-implant overdentures: one-year report. Clin Implant Dent Relat Res. 2010; 12:209-18.

26. Abi Nader S, de Souza RF, Fortin D, et al. Effect of simulated masticatory loading on the retention of stud attachments for implant overdentures. J Oral Rehabili. 2011; $38: 157-64$

27. Guédat C, Nagy U, Schimmel M, et al. Clinical performance of Locator attachments: a retrospective study with 1-8 years of follow-up. Clin Exp Dent Res. 2018; 4:132-45

28. Scrascia1 R, Martinolli M, Venezia P, Casucci A, Ortensi L, Tallarico M . Feasibility of low profile attachments to improve quality of life on patients with implant-retained mandibular overdenture: 1-year preliminary results of a multicenter prospective case series study. OHDM 2018; 17:1-5.

29. Jacob SA, Nandini V, Nayar S, Gopalakrishnan A. Occlusal principles and considerations for the osseointegrated prosthesis. J Dent Med Sci. 2013 ; 3: 47-54.
30. Lang BR, Razzoog ME. Lingualized integration: tooth molds and an occlusal scheme for edentulous implant patients. Implant Dent. 1992; 1:204-11.

31. Kim Y, Oh TJ, Misch CE, Wang HL. Occlusal considerations in implant therapy: clinical guidelines with biomechanical rationale. Clin Oral Implants Res. 2005; 16:26-35.

32. Boven GC, Meijer HJA, Vissink A, Raghoebar GM. Maxillary implant overdentures retained by use of bars or locator attachments: 1-year findings from a randomized controlled trial. J Prosth research. 2019; 2:15-20.

33. Cawood JI, Howell RA. A classification of the edentulous jaws. Int J Oral Maxillofac Surg. 1988; 17:232-6.

34. Lekholm U, Zarb G. Patient selection and preparation. In: Branemark PI, Zarb G, Albrektsson T, eds. Tissue integrated prosthesis: osseointegration in clinical dentistry. Chicago. Quintessence Publishing Co Inc. 1985:199-209.

35. Rosen B. Radiological templates and CAD/CAM surgical guides. A literature review J of IMAB. 2016; 22:285-95.

36. Osman R, Alan G.T.P, Sunyoung M. Prosthodontic Maintenance of Maxillary Implant Overdentures: A Systematic Literature Review Int J Prosthodont 2012; 25:381-91

37. Naert I., Alsaadi G, Quirynen M. Prosthetic aspects and patient satisfaction with twoimplant- retained mandibular overdentures: a 10- year randomized clinical study. Int J of Prosthodont 2004 ;17: 401-10.

38. Abdelhamid A M, Hanno K I, Imam M H. A prospective cross-over study to evaluate the effect of two different occlusal concepts on the masseter muscle activity in implant-retained mandibular overdentures. Int J of Impl Dent. 2015; 1:32.

39. Kawano F, Ohguri T, Ichikawa T, Mizuno I, Hasegawa A. Shock absorbability and hardness of commercially available denture teeth. Int J Prosthodont. 2002; 15:243-7.

40. Yoo J S, Kwon K R, Noh K, Lee H, Paek J. Stress analysis of mandibular implant overdenture with locator and bar/ clip attachment: Comparative study with differences in the denture base length. J Adv Prosthodont. 2017; 9:143-51.

41. Massad J, Ahuja S, Wicks R, and Charles J. Treating a Patient With Inadequate Restorative Space. Dent Today. 2019; 36:110-6.

42. Schneider AL, Kurtzman GM. Restoration of divergent free-standing implants in the maxilla. J Oral Implantol. 2002; 28:113-6. 
43. Nikolopoulou F, Ktena-Agapitou P. Rationale for choices of occlusal schemes for complete denture supported by implants .J of Oral Imp.2006; 4:200-3.

44. Verma M, Nanda A, Sood A. Principles of occlusion in implant dentistry. J Int Clin Dent Res Organ 2016; 7:27-33.

45. Akca K, Cavusoglu Y, Sagirkaya E, Cehreli MC. Earlyloaded one-stage implants retaining mandibular overdentures by two different mechanisms: 5-year results. Int J Oral Maxillofac Impl. 2013; 28:824-30.

46. Troeltzsch M, Troeltzsch V, Brodine AH, Frankenberger R, Messlinger K, Troeltzsch M. Clinical performance and peri-implant parameters of 132 implants supporting locator-retained overdentures: a case series of 33 patients. Int J Oral Maxillofac Impl. 2013; 28:1132-9.

47. Vere J, Hall D, Patel R, Wragg P. Prosthodontic maintenance requirements of implant-retained overdentures using the locator attachment system. Int J Prosthodont. 2012; 25:392-4.
48. Miler A, Correia ARM, Rocha JMC, Campos JCR, da Silva M. Locator(R) attachment system for implant overdentures: a systematic review. Stomato. 2017; 19:124-9.

49. Stephens GJ, di Vitale N, O’Sullivan E. The influence of inter implant divergence on the retention characteristics of locator attachments, a laboratory study. J Prosthodont 2014; 23:467-75.

50. Uludag B, Polat S, Sahin V. Effects of implant angulations and attachment configurations on the retentive forces of locator attachment-retained overdentures. Int J Oral Maxillofac Implants 2014; 29:1053-57.

51. Rabbani S, Juszczyk AS, Clark RK. Investigation of retentive force reduction and wear of the locator attachment system with different implant angulations. Int J Oral Maxillofac Impl 2015; 30:556-63.

52. Kimoto S, Pan S, Drolet N, Fiene J S. Rotational movements of mandibular two-implant overdentures . Clin Oral Imp Res. 2009; 20:838-43. 